\title{
$13 q$ Deletion in a Girl Contributing to Antenatal Stroke, Insulin Resistance and Lymphedema Praecox: Expanding the Clinical Spectrum
}

\author{
Caroline Ponmania ${ }^{a, c}$, Dinesh Giri ${ }^{b, c}$, Khalid Hussain ${ }^{a}$, Senthil Senniappan ${ }^{\text {b, d }}$
}

\begin{abstract}
The phenotypic description of $13 q$ deletion syndrome is dependent on the location and size of the deleted segment. The syndrome is divided into three groups based on the location of the deletion relative to chromosomal band 13q32. Groups 1 (proximal to q32) and 2 (including q32) have shown distinctive phenotypes including mental retardation and growth deficiency, whereas group 3 (q33-34 deletion) is defined by the presence of mental retardation but usually the absence of major malformations. 13q deletion has been associated with factor VII and X deficiencies. We report a 10-year-old girl with cytogenetically detectable 13q33.3-34 deletion (group 3) and antenatally detected factor VII deficiency leading to stroke in utero and consequently hemiplegia at birth. This is the first report of a $13 q$ deletion associated with factor VII deficiency leading to antenatal stroke. Our patient also developed rapidly progressive obesity and lymphedema praecox which have not been previously reported with $13 \mathrm{q}$ deletion.
\end{abstract}

Keywords: $13 \mathrm{q}$ deletion; Neonatal stroke; Obesity; Lymphedema praecox

\section{Introduction}

$13 \mathrm{q}$ deletion is an example of a rare chromosomal deletion syndrome and about 180 cases have been reported in the medical literature. The clinical features associated with $13 q$ deletion include moderate to severe mental and growth retardation,

Manuscript accepted for publication March 27, 2015

aDepartment of Paediatric Endocrinology, Great Ormond Street Hospital for Children, London, WC1N 3J, UK

bDepartment of Paediatric Endocrinology, Alder Hey Children's Hospital NHS Trust, Liverpool, L12 2AP, UK

${ }^{\mathrm{c}}$ Caroline Ponmani and Dinesh Giri have contributed equally to the manuscript.

${ }^{\mathrm{d} C}$ Corresponding Author: Senthil Senniappan, Department of Paediatric Endocrinology, Alder Hey Children's Hospital NHS Trust, Liverpool, UK.

Email: senthilkss@yahoo.co.uk

doi: http://dx.doi.org/10.14740/jmc2108w craniofacial dysmorphisms, hand and foot anomalies, brain, heart and kidney defects $[1,2]$. A translocation or deletion involving the region 13q33.1-34 results in low concentrations of coagulation factors [3]. Clinically this may or may not be associated with bleeding. Sub-clinical factor VII deficiency associated with a 46, XY, $\mathrm{t}(13 ; \mathrm{Y})(\mathrm{q} 11 ; \mathrm{q} 34)$ translocation and probable deletion of a terminal segment of $13 \mathrm{q}$ manifesting as elevated prothrombin time (PTT) has been reported [4].

We report an unusual presentation of 13q deletion. In our child factor VII assays showed a level of less than $3 \mathrm{IU} / \mathrm{dL}$ in utero resulting in intracranial hemorrhage. However factor VII levels increased spontaneously without treatment and although she continued to have an abnormal clotting profile with a raised PTT, there have been no symptoms of bruising or bleeding in the postnatal period.

\section{Case Report}

A baby girl was born at 39 weeks to non-consanguineous parents by emergency section for fetal distress in a good condition with a birth weight of $2.3 \mathrm{~kg}$. The baby was noted to have a paucity of movement of the left side of the body and was diagnosed to have left sided hemiplegia subsequently. Antenatally, an ultrasound scan done at 22 weeks showed right ventriculomegaly with caudothalamic groove atrophy, which was thought to represent earlier hemorrhage. Antibody titers for toxoplasma, rubella, cytomegalovirus and herpes infections were negative. The fetal blood sampling showed a normal platelet count. Maternal platelet counts were normal and there was no history of maternal intake of aspirin, antiplatelet medications, anticoagulants or any other drug ingestion. Functional factor VII assay performed antenatally, demonstrated a factor VII level of less than $3 \mathrm{IU} / \mathrm{dL}$ (normal range $>50 \mathrm{IU} / \mathrm{dL}$ ). Cytogenetic analysis of the amniotic fluid revealed a terminal deletion of chromosome 13 with a breakpoint at 13q33.3 (46XX del (13) (q33.3) ish del (13) (q33.3) (wcp13+, D13S327-)). The genotype was confirmed in the postnatal period. A probe for the subtelomeric region of chromosome 13 (D13S327) demonstrated a small distal long arm deletion in the anomalous chromosome. A cytogenetic analysis performed on both the parents did not reveal any abnormalities.

Functional factor assays performed in the postnatal period 


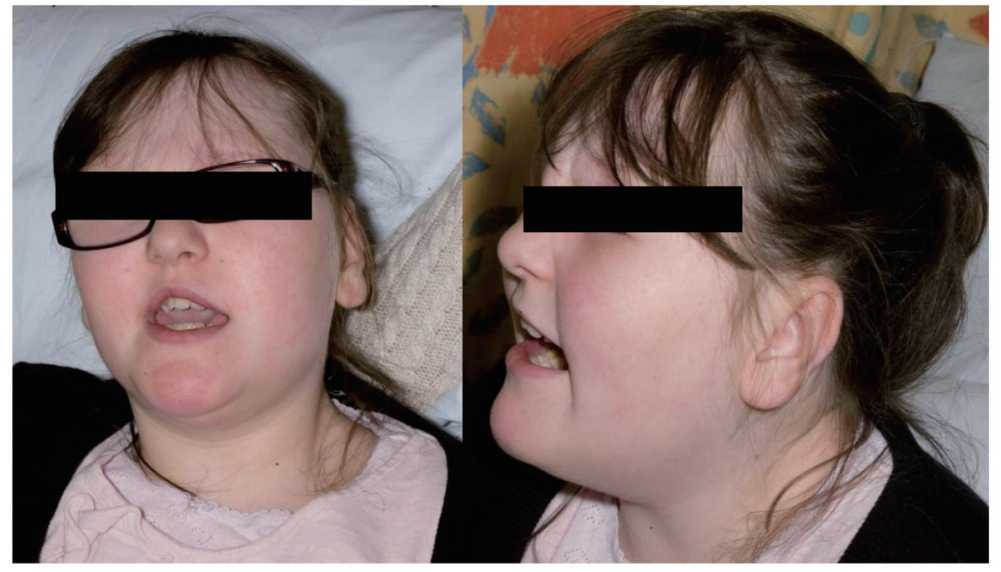

Figure 1. Dysmorphic features include prominent forehead, triangular face, high nasal root, thin upper lip, downturned corners of the mouth, and a small, pointed chin.

showed an increase in the factor VII level to $8 \mathrm{IU} / \mathrm{dL}$ from an antenatal assay level of less than $3 \mathrm{IU} / \mathrm{dL}$. At 3 months of age her factor VII levels spontaneously rose to $35 \mathrm{IU} / \mathrm{dL}$. There was no history of bruising epistaxis or bleeding during childhood. The factor $\mathrm{X}$ assay was subsequently within the normal range.

The dysmorphic features comprised of prominent forehead, triangular face, almond shaped eyes with upslanting palpable fissures, mild ptosis, high nasal root, hypoplastic alae nasi with prominent columella, thin upper lip, downturned corners of the mouth, and a small pointed chin (Fig. 1). She also developed swelling of both lower limbs, which progressively increased with time. A series of abdominal ultrasounds showed no evidence for obstruction of the inferior vena cava. A clinical diagnosis of lymphedema praecox was made.

She was noted to be failing to thrive due to severe gastroesophageal reflux. Nissen's fundoplication was performed at 8 years of age. The surgical procedure was not associated with abnormal bleeding. She was subsequently noted to gain excessive weight. At 10 years of age, the patient's body mass index (BMI) was 29.5 (+3.07 standard deviation score) with microcephaly (below 0.4 th centile).

Endocrine investigations to identify the cause of obesity including a 24-h glucose and cortisol profile, urinary steroid profile, adrenal androgens, thyroid function tests, and baseline pituitary function tests were within normal limits. An oral glucose tolerance test showed evidence of insulin insensitivity (Table 1) with the peak plasma insulin level of $170 \mathrm{mU} / \mathrm{L}$ at $30 \mathrm{~min}$ and peak plasma glucose of $124 \mathrm{mg} / \mathrm{dL}$. She was commenced on metformin at a dose of $500 \mathrm{mg}$ twice daily and follow-up of 12 months did not reveal any significant benefit.

\section{Discussion}

Partial deletions in chromosome $13 \mathrm{q}$ lead to variable phenotypes based on the size and position of the deleted region [5]. While distal deletions are closely associated with severe phenotypes, proximal deletions tend to cause fewer major anomalies, with the exception of retinoblastoma [6].

In our patient, the deletion occurred before the coding region for factor VII, with the break point occurring at $13 \mathrm{q} 33.3$ (Table 2). This possibly led to antenatally detected very low levels of factor VII leading to intracranial hemorrhage. This is the first case report of $13 q$ deletion associated with factor VII deficiency leading to antenatal stroke. Interestingly the factor VII levels improved spontaneously in the postnatal period. The reason for this fluctuation in the factor VII levels remains unclear. In addition to factor VII deficiency, the deletion of COL4A1 (OMIM 120130) and COL4A2 (OMIM 120090) genes, which have been mapped to chromosome 13q33.3-34 (Table 2) could have contributed to the hemorrhagic stroke in the antenatal period [7].

The human insulin receptor substrate 2 (IRS2) (OMIM 600797 ) is localized on chromosome 13q34 (Table 2). This gene encodes the IRS2, a cytoplasmic signaling molecule that mediates effects of insulin, insulin-like growth factor 1, and other cytokines [8]. Homozygous deletion of IRS2 in mice is known to generate insulin resistance which is particularly pronounced in liver [9]. Mice lacking IRS2 develop diabetes due to peripheral insulin resistance, failed hypothalamic regulation of appetite and $\beta$-cell insufficiency [10]. Our patient had a heterozygous deletion of IRS2 gene (Table 2) which we postulate

Table 1. Oral Glucose Tolerance Test (OGTT)

\begin{tabular}{|c|c|c|c|c|c|c|c|c|}
\hline & $-30 \mathrm{~min}$ & $0 \mathrm{~min}$ & $30 \mathrm{~min}$ & $60 \mathrm{~min}$ & $90 \mathrm{~min}$ & $120 \mathrm{~min}$ & $150 \mathrm{~min}$ & $180 \mathrm{~min}$ \\
\hline Glucose (mg/dL) & 82 & 79 & 154 & 80 & 106 & 99 & 70 & 68 \\
\hline Insulin (mU/L) & 13.7 & 14.6 & 170 & 59.5 & 92.9 & 72.6 & 30.7 & 14.7 \\
\hline
\end{tabular}

Homeostasis model of assessment-insulin resistance (HOMA-IR): 2.8. 
Table 2. Genes Mapping to Chromosome 13q33.3-34 (Ensembl/Biomart)

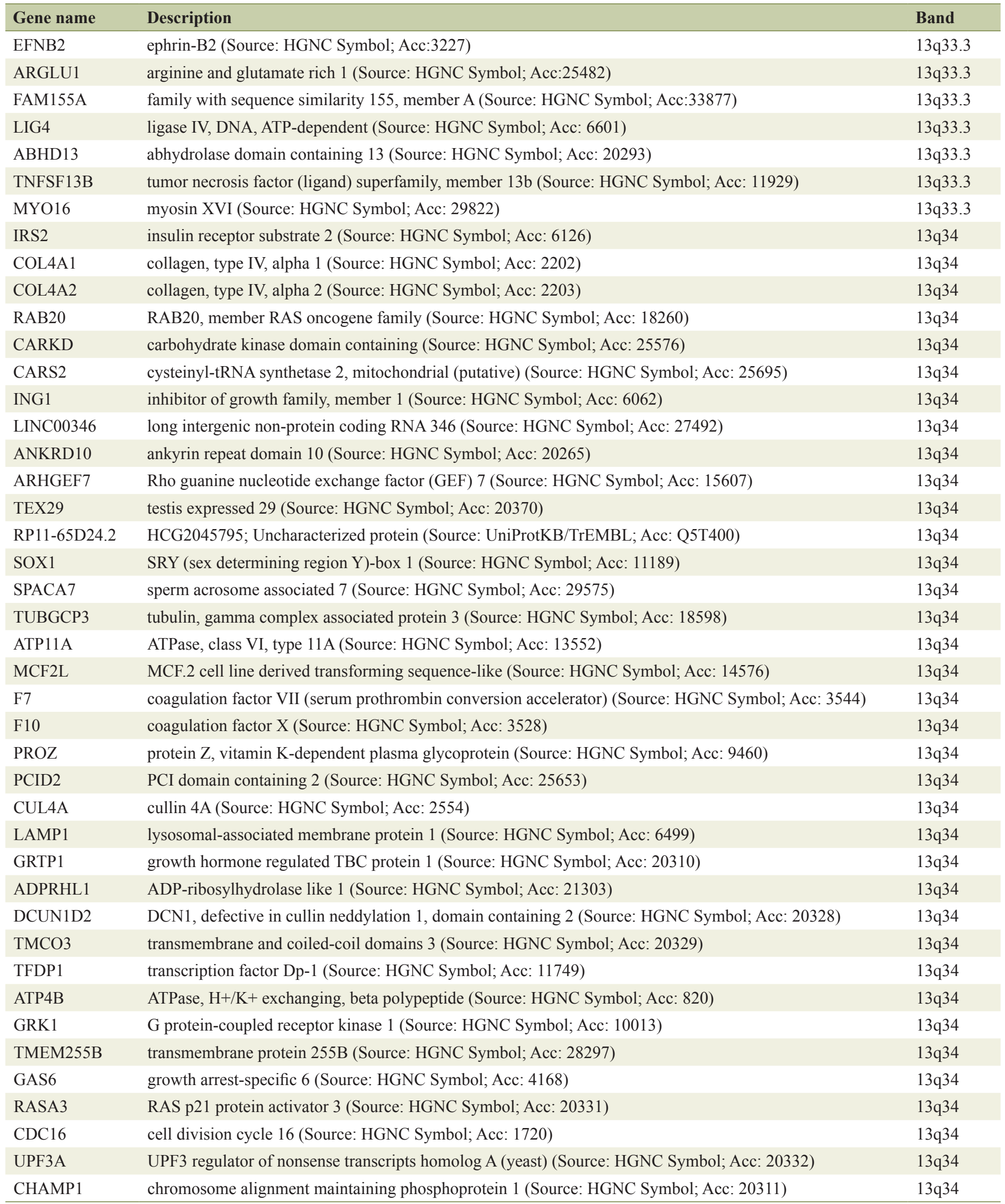


to be the cause of insulin resistance. Our patient has mobility issues that reduce the calorie expenditure in addition to the behavioral difficulties that make calorie restriction very difficult. These factors in association with the genetic predisposition for insulin resistance due to IRS2 deletion possibly act together in contributing to the obesity.

Primary lymphedema (lymphedema praecox), a disorder causing persistent swelling in an extremity, is rare in childhood [11]. The influences of estrogen and inflammation are thought to be important etiologic factors in primary lymphedema [12]. This is the first case report of lymphedema praecox in association with $13 q$ deletion. She did not have any other cause like trauma, illness, pelvic mass or surgery that could have contributed to the lymphedema. No genetic etiology for lymphedema praecox has been identified so far; hence the exact genetic link between $13 \mathrm{q}$ deletion and lymphedema is not clear.

\section{Conclusion}

While $13 q$ deletion syndromes are well recognized, this is the first reported case report of antenatal, hemorrhagic stroke secondary to factor VII deficiency. In the index case, the deletion has occurred just before the coding region for factor VII leading to intracranial hemorrhage antenatally. A combination of genetic (deletion of IRS2) and environmental factors (diet and exercise) possibly contributes to the obesity and insulin resistance. This is the also first case report of lymphedema praecox in association with $13 \mathrm{q}$ deletion.

\section{Competing Interests}

None.

\section{References}

1. Brooks BP, Meck JM, Haddad BR, Bendavid C, Blain D, Toretsky JA. Factor VII deficiency and developmental abnormalities in a patient with partial monosomy of $13 q$ and trisomy of $16 \mathrm{p}$ : case report and review of the literature. BMC Med Genet. 2006;7:2.

2. Luo J, Balkin N, Stewart JF, Sarwark JF, Charrow J, Nye
JS. Neural tube defects and the $13 \mathrm{q}$ deletion syndrome: evidence for a critical region in 13q33-34. Am J Med Genet. 2000;91(3):227-230.

3. Hewson MP, Carter JM. Severe congenital Factor VII deficiency associated with the $13 \mathrm{q}$ deletion syndrome. Am J Hematol. 2002;71(3):232-233.

4. Pfeiffer RA, Ott R, Gilgenkrantz S, Alexandre P. Deficiency of coagulation factors VII and X associated with deletion of a chromosome 13 (q34). Evidence from two cases with 46,XY,t(13;Y)(q11;q34). Hum Genet. 1982;62(4):358-360.

5. Kirchhoff M, Bisgaard AM, Stoeva R, Dimitrov B, Gillessen-Kaesbach G, Fryns JP, Rose H, et al. Phenotype and $244 \mathrm{k}$ array-CGH characterization of chromosome 13q deletions: an update of the phenotypic map of 13q21.1-qter. Am J Med Genet A. 2009;149A(5):894905.

6. Ballarati L, Rossi E, Bonati MT, Gimelli S, Maraschio P, Finelli P, Giglio S, et al. 13q Deletion and central nervous system anomalies: further insights from karyotype-phenotype analyses of 14 patients. J Med Genet. 2007;44(1):e60.

7. Jeanne M, Labelle-Dumais C, Jorgensen J, Kauffman WB, Mancini GM, Favor J, Valant V, et al. COL4A2 mutations impair COL4A1 and COL4A2 secretion and cause hemorrhagic stroke. Am J Hum Genet. 2012;90(1):91101.

8. Yenush L, White MF. The IRS-signalling system during insulin and cytokine action. Bioessays. 1997;19(6):491500.

9. Withers DJ, Gutierrez JS, Towery H, Burks DJ, Ren JM, Previs S, Zhang Y, et al. Disruption of IRS-2 causes type 2 diabetes in mice. Nature. 1998;391(6670):900-904.

10. Kubota N, Tobe K, Terauchi Y, Eto K, Yamauchi T, Suzuki R, Tsubamoto Y, et al. Disruption of insulin receptor substrate 2 causes type 2 diabetes because of liver insulin resistance and lack of compensatory beta-cell hyperplasia. Diabetes. 2000;49(11):1880-1889.

11. Lazareth I. [Classification of lymphedema]. Rev Med Interne. 2002;23(Suppl 3):375s-378s.

12. Kerchner K, Fleischer A, Yosipovitch G. Lower extremity lymphedema update: pathophysiology, diagnosis, and treatment guidelines. J Am Acad Dermatol. 2008;59(2):324-331. 